\title{
Disease modeling and drug screening for neurological diseases using human induced pluripotent stem cells
}

\author{
Xiao-hong $\mathrm{XU}^{1,2}$, Zhong $\mathrm{ZHONG}^{2, *}$ \\ ${ }^{1}$ Department of Histology and Embryology, Harbin Medical University, Harbin 150081, China; ${ }^{2}$ Regenerative Medicine DPU, \\ GlaxoSmithKline (China) R\&D Co, Ltd, Shanghai 201203, China
}

\begin{abstract}
With the general decline of pharmaceutical research productivity, there are concerns that many components of the drug discovery process need to be redesigned and optimized. For example, the human immortalized cell lines or animal primary cells commonly used in traditional drug screening may not faithfully recapitulate the pathological mechanisms of human diseases, leading to biases in assays, targets, or compounds that do not effectively address disease mechanisms. Recent advances in stem cell research, especially in the development of induced pluripotent stem cell (iPSC) technology, provide a new paradigm for drug screening by permitting the use of human cells with the same genetic makeup as the patients without the typical quantity constraints associated with patient primary cells. In this article, we will review the progress made to date on cellular disease models using human stem cells, with a focus on patient-specific iPSCs for neurological diseases. We will discuss the key challenges and the factors that associated with the success of using stem cell models for drug discovery through examples from monogenic diseases, diseases with various known genetic components, and complex diseases caused by a combination of genetic, environmental and other factors.
\end{abstract}

Keywords: induced pluripotent stem cells; embryonic stem cells; neurodegenerative diseases; disease modeling; drug screening

Acta Pharmacologica Sinica (2013) 34: 755-764; doi: 10.1038/aps.2013.63; published online 20 May 2013

\section{Introduction}

The causal relationships between genes and diseases are most commonly studied in animal models using gain- or loss-offunction mutations. However, in many cases, the genetic, anatomical and physiological differences between animals and humans present a challenge for projecting these relationships to human diseases. Thus far, preclinical treatments that show success in animal models have not always translated well into clinical trials, further highlighting the flaws of using the existing animal models to recapitulate human diseases ${ }^{[1,2]}$. Moreover, access to human tissues other than blood is scarce, and the available postmortem tissues usually only represent the late-stage characteristics of disease progression. Due to these limitations, immortalized human cell lines with genetic modifications are commonly used as cellular models for drug screening ${ }^{[3]}$. Because of the changes introduced by immortalization, it is often questioned whether these cellular systems accurately model primary human cells.

\footnotetext{
* To whom correspondence should be addressed.

E-mail zhong.z.zhong@gsk.com

Received 2012-12-31 Accepted 2013-04-22
}

Recent advances in stem cell research, especially the development of induced pluripotent stem cell (iPSC) technology ${ }^{[4,5]}$, provide new opportunities which may overcome many of the challenges and shortcomings associated with disease modeling and drug screening ${ }^{[6-9]}$. An ideal drug screening platform would provide reproducible and quantifiable disease-relevant phenotypes in a scalable cell population. iPSC-derived cells have advantages over primary cells and immortalized cell lines because they can provide inexhaustible, scalable, and genetically relevant sources for cell-based drug screening ${ }^{[10,11]}$. Many neurological disease phenotypes can be measured on high-content imaging platforms through changes in cellular morphology, such as soma size, neurite length, or spine density of neurons ${ }^{[12]}$. In addition, changes in biochemical activity and gene expression could also be used as assay readouts for drug screens. Therefore, iPSCs will likely become an attractive drug discovery platform for neurological diseases.

In this review, we will discuss the progress made to date on cellular disease modeling and drug screening using stem cell systems (ie, differentiated cells from stem cells or iPSCs), with a focus on iPSCs from patients with neurological diseases. We review a few critical questions for disease modeling based on 
iPSCs and analyze the success and challenges of using these newly available cellular models for drug discovery.

\section{Linking cellular phenotypes in iPSC models to genetic defects of monogenic diseases}

Given that many monogenic diseases affect specific cell types with high penetrance, it is reasonable to suggest that the development of disease-relevant phenotypes is likely to be most predictable from iPSCs carrying the same genetic makeup. We will use two examples, Spinal Muscular Atrophy (SMA) and Machado-Joseph Disease (MJD), to illustrate that disease modeling with iPSCs requires connecting specific cellular phenotypes with key disease pathologies.

SMA is an early-onset neurological disease caused by the selective loss of the lower motor neurons, with symptoms including progressive muscular atrophy, paralysis and death. This disease is caused by a deletion or mutation in the survival motor neuron 1 (SMN1) gene that results in significantly reduced expression of the full-length SMN protein ${ }^{[13]}$. The major function of SMN is to mediate the assembly of small nuclear ribonuclear proteins (snRNPs) and enable axonal mRNA transport and local mRNA processing. SMN reduction has been shown to cause both altered pre-mRNA splicing of specific target genes and reduced axonal transport of specific mRNAs to synapses, leading to the selective degeneration of the lower a-motor neurons ${ }^{[14]}$. Moreover, some evidence has demonstrated that SMN can synergize with Bcl-2 to inhibit Fas- or Bax-mediated neuronal apoptosis ${ }^{[15]}$.

Ebert $e a{ }^{[16]}$ published the first study demonstrating that human iPSCs could be used to model a genetically inherited disease. This study showed that motor neurons derived from SMA iPSCs cultured for six weeks were selectively reduced in both number and size compared with those from the control groups. In addition, SMN aggregates were also reduced in the SMA iPSCs and their differentiated motor neurons. It was shown that valproic acid and tobramycin rescued the decreased number of SMN-rich structures (gems) in the SMA iPSCs. It is probable that the observed motor neuron death represented a disease-relevant phenotype that correlated with the molecular mechanism of SMN reduction. In a follow-up study, the pivotal cell death signaling mechanisms in SMA iPSC-derived motor neurons were investigated using the original patient iPSC line and a newly generated virus-free line from a second SMA patient ${ }^{[17]}$.

The activation of the Fas ligand-mediated apoptotic pathway via caspase- 8 and -3 was observed in the cell death of SMA iPSC-derived motor neurons, and this cell death could be prevented by either Fas-blocking antibodies or a caspase-3 inhibitor ${ }^{[17]}$. The causal relationship between the SMN gene defects and the selective loss of motor neurons was further demonstrated by Chang et al ${ }^{[18]}$, who reported that ectopic SMN expression in five SMA iPSC lines restored normal motor neuron differentiation and rescued the delayed neurite outgrowth. Therefore, they concluded that the robust phenotypes, including the reduced motor neuron production and the slower neurite development observed in motor neurons dif- ferentiated from the multiple SMA iPSC lines, are likely due to the strong genetic determinant of the SMN1 defect.

MJD, or Spinocerebellar Ataxia Type 3 (SCA3), is a lateonset inherited neurodegenerative disease caused by the abnormal expansion of "CAG" trinucleotide repeats in the ataxin 3 (ATXN3) gene. Moreover, the size of the CAG repeat in MJD inversely correlates with the age of disease onset and directly correlates with disease severity. The ATXN3 protein is a deubiquitinating enzyme (DUB) and helps regulate the stability or activity of many cellular pathway proteins in various physiological events. The expansion of the polyglutamine (polyQ) tract in ATNX3 might alter the protein conformation, leading to changes in its interactions with native partners and to the formation of insoluble aggregates ${ }^{[19]}$. The formation of ATNX3-containing aggregates is thought to trigger disease initiation and progression with symptoms of progressive cerebellar ataxia, although it is unknown how the aggregates elicit neurotoxicity ${ }^{[20]}$.

Recently, Koch et al ${ }^{[21]}$ established MJD patient-specific iPSC models and demonstrated that the L-glutamate-induced excitation of MJD iPSC-derived neurons initiated calciumdependent proteolysis of ATXN3, followed by the formation of aberrant insoluble aggregates. Importantly, this phenotype was specifically observed in MJD iPSC-derived neurons, but not in the patient's fibroblasts, iPSCs, or differentiated glial cells. These findings could effectively explain the reason for neuron-specific degeneration in MJD, which conventional approaches have not been able to uncover. These types of neuron-dominant phenotypes demonstrate the great potential advantages of iPSC technology both in modeling monogenic neurodegenerative diseases and in studying the underlying disease mechanisms.

Other monogenic disease-specific iPSCs have been generated and display possible disease phenotypes (Table 1), including Huntington's disease (HD) ${ }^{[22]}$, Fragile X syndrome ${ }^{[23]}$, Prader-Willi Syndrome (PWS) ${ }^{[24]}$, Duchenne Muscular Dystrophy (DMD) $)^{[25]}$, Familial Dysautonomia (FD ${ }^{[26]}$, and Down's syndrome (DS) ${ }^{[27]}$.

\section{Diseases that are difficult to model using iPSCs}

There are many reports that disease-specific iPSCs have been generated with little or no phenotype detected. For example, Song $e a a l^{[28]}$ generated iPSCs from skin cells obtained from a relapsing-remitting multiple sclerosis (MS) patient and differentiated the MS iPSCs into mature neural lineages. However, the MS iPSC-derived neurons exhibited normal properties of functional neurons and only displayed minor differences in their electrophysiological characteristics. We speculate that the following reasons could account for the challenges of detecting disease phenotypes in iPSC models.

\section{Late-onset diseases}

Many neurodegenerative diseases are late-onset diseases, and their key phenotypes may not manifest easily within a short period of time in culture. Alzheimer's disease (AD) is a lateonset disease characterized by amyloid plaques, neurofibril- 
Table 1. Selected examples of monogenic neurological diseases modeled with patient-specific iPSCs.

\begin{tabular}{|c|c|c|c|c|c|c|}
\hline Disease & Genetic defects & $\begin{array}{l}\text { iPSC-derived } \\
\text { cell types }\end{array}$ & Phenotype demonstrated & $\begin{array}{l}\text { Genetic } \\
\text { rescue }\end{array}$ & $\begin{array}{l}\text { Drug } \\
\text { test }\end{array}$ & $\begin{array}{l}\text { Refer- } \\
\text { ences }\end{array}$ \\
\hline $\begin{array}{l}\text { Spinal muscular } \\
\text { atrophy (SMA) }\end{array}$ & Mutation in SMN1 & Motor neurons & $\begin{array}{l}\text { Loss of SMN1 gene expression; } \\
\text { Reduced size and number of motor neurons. }\end{array}$ & Yes & Yes & [16-18] \\
\hline $\begin{array}{l}\text { Machado-Joseph } \\
\text { disease (MJD) }\end{array}$ & $\begin{array}{l}\text { Expanded CAG repeat in } \\
\text { ATXN3 gene }\end{array}$ & $\begin{array}{l}\text { Neurons and } \\
\text { glial cells }\end{array}$ & $\begin{array}{l}\text { Excitation-induced ATXN3 aggregation in } \\
\text { differentiated neurons. }\end{array}$ & No & Yes & [94] \\
\hline $\begin{array}{l}\text { Familial } \\
\text { dysautonomia } \\
\text { (FD) }\end{array}$ & Mutation in IKBKAP & $\begin{array}{l}\text { Neural crest precursors } \\
\text { and neurons }\end{array}$ & $\begin{array}{l}\text { Increased abnormal splicing in differentiated } \\
\text { neural crest; } \\
\text { Decreased neurogenesis and migration } \\
\text { defects. }\end{array}$ & No & Yes & {$[26]$} \\
\hline $\begin{array}{l}\text { Huntington's } \\
\text { disease (HD) }\end{array}$ & $\begin{array}{l}\text { Expanded CAG repeat in } \\
\text { HTT gene }\end{array}$ & $\begin{array}{l}\text { Neural stem cells, striatal } \\
\text { neurons, and astrocytes }\end{array}$ & $\begin{array}{l}\text { Enhanced caspase } 3 / 7 \text { activity after growth } \\
\text { factor withdrawal; } \\
\text { Increase in lysosomal activity in HD-iPS cells; } \\
\text { Vacuolation in astrocytes; } \\
\text { Increased vulnerability to stressors and } \\
\text { BDNF withdrawal in striatal neurons. }\end{array}$ & Yes & No & $\begin{array}{l}{[22]} \\
{[95]} \\
{[96]} \\
{[63]}\end{array}$ \\
\hline
\end{tabular}

lary tangles (NFTs), and selective neuronal loss in the cerebral cortex and hippocampus ${ }^{[29]}$. Recently, several groups reported the derivation of patient-specific iPSCs with amyloid precursor protein (APP) or Presenilin-1/2 (PS1/2) gene mutations and observed increased expression of the $\beta$-amyloid $(A \beta)$, phospho-Tau, and activated GSK-3 $\beta^{[30-32]}$ proteins in these iPSC-derived neurons. These proteins are the critical markers in the pathological process of APP proteolysis and the formation of NFTs. However, selective cortical neuronal loss and damage to synaptic functions, which are the most important pathological changes in AD patients, were not observed. It is believed that the absence of important disease phenotypes may be a result of the immature characteristics of the neuronal culture as well as of the lack of appropriate stressors associated with ageing.

\section{Non-cell-autonomous diseases}

Selective susceptibility of neuronal cell types in many neurodegenerative diseases, including amyotrophic lateral sclerosis (ALS), Parkinson's disease (PD), AD, HD, and the spinal cerebellar ataxias $(\mathrm{SCAs})^{[33]}$, can be induced by pathological changes in the neurons as well as in their interacting partners. ALS is a neurodegenerative disease that is characterized by motor neuron death in the spinal cord and brain stem ${ }^{[34,35]}$. In the case of the familial form of ALS, which carries the superoxide dismutase (SOD1) gene mutation, disease-specific defects will only manifest when motor neurons are co-cultured with primary cortical glial cells from SOD1G93A transgenic mice ${ }^{[34]}$ or astrocytes isolated from human fetal cerebral cortex with Lenti-SOD $^{\mathrm{G} 37 \mathrm{R}}$ over-expression ${ }^{[35]}$. Although mutations in the ubiquitously expressed SOD1 gene lead to a dominant, inherited form of ALS, motor neurons derived from SOD1 iPSCs did not show any functional defects or cell loss ${ }^{[36]}$. This observation differs from the finding that iPSCs from patients suffering from a different familial form of ALS that carries a Tar DNA binding protein-43 (TDP-43) mutation will give rise to motor neurons with decreased survival in longitudinal studies $^{[37,38]}$. Therefore, the disease phenotype for the noncell-autonomous form of ALS requires proper co-culture systems. The advancement of microfluidic ${ }^{[39]}$ or 3-dimensional ${ }^{[40]}$ platforms may offer new ways to better mimic physiological, spatial, and temporal microenvironments for cell growth.

\section{Diseases that are partly attributed to environmental stressors}

Diseases that are caused by complex environmental and genetic factors may not manifest functional defects in iPSC models under basal culture conditions and might require the use of stressors to challenge the cell cultures. PD is one of the late-onset neurodegenerative disorders and is characterized by motor symptoms attributed to the death of dopamine-secreting cells in the pars compacta region of the substantia nigra in the midbrain ${ }^{[41]}$. Recently, iPSC lines carrying the a-synuclein (SNCA) locus triplication ${ }^{[42,43]}$ or mutations in leucine-rich repeat kinase 2 (LRRK2) $^{[44,45]}$, PTEN-induced putative kinase 1 $(\mathrm{PINK} 1)^{[46,47]}$, or parkin $(\mathrm{PARKN})^{[48]}$ have been generated. Although PINK1 is a genetic factor for PD, it has low genetic penetrance and requires proper environmental triggers for disease onset.

Seibler et $a^{[47]}$ generated human iPSCs from PD patients carrying either nonsense or missense mutations in the PINK1 gene, but further analysis did not reveal any defects in the generation and survival of the dopaminergic (DA) neurons differentiated from these mutant PINK1 iPSCs. However, they have observed some detectable cellular defects upon treatment with the mitochondrial stress inducer valinomycin. Therefore, it may be necessary to expose cells to the relevant biological, chemical or environmental stressors to reveal the underlying disease phenotypes when modeling late-onset, non-cell-autonomous, and complex multi-factorial diseases using iPSCs. 
Progress of modeling non-monogenic neurological diseases with iPSCs

Some familial forms of neurodegenerative diseases such as PD, ALS and AD have strong genetic components, and therefore, attempts have been made to model these diseases using iPSCs, with some success (Table 2). However, diseases caused by a combination of genetic, environmental and/or other factors are difficult to model, as the epigenetic marks left by environmental and other factors are most likely erased in the process of reprogramming (Table 3). As a result, these cells may lose their ability to model complex multi-factorial disorders, especially if the epigenetic changes are critical to the manifestation of symptoms.

Of the many genetic mutations linked to $\mathrm{PD}$, mutations in SNCA and LRRK2 were shown to be dominant and highly penetrant. Using PD iPSC models carrying the SNCA triplication, Byers et al ${ }^{[42]}$ found that the accumulation of a-synuclein and increased sensitivity to oxidative stress were specifically displayed in DA neurons derived from patient iPSCs; a similar a-synuclein pathology was also observed by another group ${ }^{[43]}$. Nguyen et $a l^{[44]}$ found that the DA neurons derived from iPSCs carrying the G2019S mutation in the LRRK2 gene showed increased expression levels of a-synuclein and key oxidative stress-response genes, including HSPB1, NOX1 and MAOB. Moreover, the neurons carrying the LRRK2 (G2091S) mutation were more sensitive to stress agents such as peroxide and 6-hydroxydopamine (6-OHDA). Interestingly, SanchezDanes $e a l^{[45]}$ found that DA neurons that were differentiated from iPSCs of either idiopathic PD or LRRK2 PD showed similar morphological alterations, including reduced numbers of neurites and neurite arborization and the accumulation of autophagic vacuoles. The genetic changes in these idiopathic PD patients captured in the corresponding iPSC lines might be sufficient to specify the functional changes in the differentiated neurons. If these results can be confirmed in future studies, it will open up possibilities for modeling sporadic diseases.

Schizophrenia (SCZD) is a complex psychiatric disorder in which genetics, early environmental factors, neurobiology, and psychological and social processes appear to be important contributors. It has been thought that a developmental disruption of neural connectivity is tightly associated with the symptoms of SCZD, which include thought disturbances, hallucinations, and decay of social and cognitive performances ${ }^{[49]}$. Post-mortem studies revealed reduced brain volume, cell size, and spine density and abnormal neural distribution in the prefrontal cortex and hippocampus of the SCZD brain ${ }^{[50]}$.

Table 2. Selected examples of multigenic neurological diseases modeled with patient-specific iPSCs.

\begin{tabular}{|c|c|c|c|c|c|c|}
\hline Disease & Genetic defects & $\begin{array}{l}\text { iPSC-derived } \\
\text { cell types }\end{array}$ & Phenotype demonstrated & $\begin{array}{l}\text { Genetic } \\
\text { rescue }\end{array}$ & $\begin{array}{l}\text { Drug } \\
\text { test }\end{array}$ & $\begin{array}{l}\text { Refer- } \\
\text { ences }\end{array}$ \\
\hline \multirow{3}{*}{$\begin{array}{l}\text { Amyotrophic lateral } \\
\text { sclerosis (ALS) }\end{array}$} & Mutation in SOD1 & Motor neurons & No answer & No & No & {$[36,65]$} \\
\hline & Mutation in VAPB & Motor neurons & Reduced VAPB expression in motor neurons. & No & No & {$[97]$} \\
\hline & Mutation in TDP-43 & Motor neurons & $\begin{array}{l}\text { Formation of cytosolic TDP- } 43 \text { aggregates; } \\
\text { Decreased neurite length; } \\
\text { Increased vulnerability to antagonism of the PI3K } \\
\text { pathway and oxidative stressors. }\end{array}$ & No & Yes & {$[37,38]$} \\
\hline \multirow[t]{2}{*}{$\begin{array}{l}\text { Rett syndrome } \\
\text { (RTT) }\end{array}$} & Mutation in MECP2 & Neurons & $\begin{array}{l}\text { Decreased synapse number, spine number and } \\
\text { soma size; } \\
\text { Elevated LINE1 retrotransposon mobility. }\end{array}$ & No & No & $\begin{array}{l}{[98-100]} \\
{[101]}\end{array}$ \\
\hline & Mutation in CDKL5 & $\begin{array}{l}\text { Glutamatergic } \\
\text { neurons }\end{array}$ & Aberrant dendritic spine structure. & No & No & {$[102]$} \\
\hline \multirow[t]{4}{*}{$\begin{array}{l}\text { Parkinson's disease } \\
\text { (PD) }\end{array}$} & Mutation in LRRK2 & $\begin{array}{l}\text { Dopaminergic } \\
\text { neurons and } \\
\text { neural stem cells }\end{array}$ & $\begin{array}{l}\text { Increased SNCA levels and vulnerability to stress } \\
\text { agents; } \\
\text { Passage-dependent deficiencies in nuclear- } \\
\text { envelope organization, clonal expansion and } \\
\text { neuronal differentiation. }\end{array}$ & Yes & Yes & $\begin{array}{l}{[44-46]} \\
{[103]}\end{array}$ \\
\hline & Mutation in PINK1 & $\begin{array}{l}\text { Dopaminergic } \\
\text { neurons }\end{array}$ & $\begin{array}{l}\text { Impaired recruitment of Parkin to mitochondria, } \\
\text { increased mitochondrial copy number and } \\
\text { upregulation of PGC-1 } \alpha \text {; } \\
\text { Increased vulnerability to cellular stressors. }\end{array}$ & Yes & Yes & {$[46]$} \\
\hline & Mutation in SNCA & $\begin{array}{l}\text { Dopaminergic } \\
\text { neurons }\end{array}$ & $\begin{array}{l}\text { Increased SNCA expression and susceptibility to } \\
\text { oxidative stress. }\end{array}$ & No & No & {$[42,43]$} \\
\hline & Mutation in PARKIN & $\begin{array}{l}\text { Dopaminergic } \\
\text { neurons }\end{array}$ & $\begin{array}{l}\text { Mitochondrial dysfunction associated } \\
\text { with increased oxidative stress and SNCA } \\
\text { accumulation. }\end{array}$ & No & Yes & {$[48]$} \\
\hline \multirow{2}{*}{$\begin{array}{l}\text { Alzheimer's disease } \\
(A D)\end{array}$} & Mutations in PS1 and PS2 & Neurons & Increased ratio of $A \beta_{42 / 40}$. & No & Yes & {$[32,104]$} \\
\hline & Duplication of APP & Neurons & $\begin{array}{l}\text { Increased } A \beta_{40} \text { production, phospho-Tau and GSK- } \\
3 \beta \text { activity. }\end{array}$ & No & Yes & {$[30,31]$} \\
\hline
\end{tabular}


Table 3. Selected examples of multi-factorial neurological diseases modeled with patient-specific iPSCs.

\begin{tabular}{|c|c|c|c|c|c|c|}
\hline Disease & $\begin{array}{l}\text { Genetic } \\
\text { defects }\end{array}$ & $\begin{array}{l}\text { iPSC-derived } \\
\text { cell types }\end{array}$ & Phenotype demonstrated & $\begin{array}{c}\text { Genetic } \\
\text { rescue }\end{array}$ & $\begin{array}{l}\text { Drug } \\
\text { test }\end{array}$ & $\begin{array}{l}\text { Refer- } \\
\text { ences }\end{array}$ \\
\hline $\begin{array}{l}\text { Sporadic Parkinson's } \\
\text { disease (SPD) }\end{array}$ & Unknown & $\begin{array}{l}\text { Dopaminergic } \\
\text { neurons }\end{array}$ & $\begin{array}{l}\text { Fewer and less branched neurites, and autophagic } \\
\text { compromise. }\end{array}$ & No answer & No & {$[45]$} \\
\hline $\begin{array}{l}\text { Sporadic Alzheimer's } \\
\text { disease (SAD) }\end{array}$ & Unknown & Neurons & $\begin{array}{l}\text { Higher levels of the pathological markers in one out of two } \\
\text { patient-derived neural cells. }\end{array}$ & No answer & Yes & {$[30]$} \\
\hline Schizophrenia (SCZD) & Unknown & Neurons & $\begin{array}{l}\text { Decreased neuronal connectivity, fewer neurites, and } \\
\text { decreased PSD95, glutamate receptor expression. }\end{array}$ & No answer & Yes & {$[51]$} \\
\hline Multiple sclerosis (MS) & Unknown & Neurons & $\begin{array}{l}\text { Neurons appear functional but have somewhat different } \\
\text { electrophysiological characteristics than controls. }\end{array}$ & No answer & No & [28] \\
\hline
\end{tabular}

However, the cell types affected in SCZD and the underlying molecular mechanisms of the disease remain unclear.

Brennand et a ${ }^{[51]}$ directly reprogrammed fibroblasts into iPSCs from four SCZD patients who displayed either childhood onset or a familial form of the disease and subsequently differentiated these iPSCs into a largely glutamatergic neuronal population. These neurons showed diminished neuronal connectivity in conjunction with decreased neurite number, PSD95 protein levels, and glutamate receptor expression, as well as altered gene expression of components of the cyclic AMP and WNT signaling pathways. Moreover, the synaptic transmission defects of the SCZD iPSC-derived neurons were ameliorated after treatment with the antipsychotic drug loxapine for three weeks, but without the detection of synaptic functional improvement as measured by electrophysiological and spontaneous calcium imaging methods. However, four other antipsychotic drugs failed to improve the neuronal connectivity, raising questions about the significance of the protective effects of loxapine in these iPSC models.

\section{The key enabling factors in cellular disease models using iPSCs}

We propose here that the following three critical factors need to be considered when using iPSCs for disease modeling and compound screens.

\section{Efficient differentiation of iPSCs into cell types impacted by diseases}

Recently, specific functional neural cells have been successfully obtained from iPSCs, including neural progenitor cells (NPCs), DA neurons, cholinergic neurons, motor neurons, astrocytes and oligodendrocytes ${ }^{[52-55]}$. However, the current differentiation methods, which are based on developmental paradigm or relevant cell fate regulation signals, require time-consuming, laborious and complicated processes and often result in a low percentage of the desired cells with immature characteristics. Therefore, it is critical for investigators to establish robust and efficient differentiation protocols for obtaining fully differentiated disease-relevant cells. Fortunately, the generation of transgenic reporter cell lines using fluorescent reporter genes under the control of cell-type-specific promoters can help to track and purify disease-relevant cells from heterogeneous differentiated cell types. For example, the HB9:GFP human embryonic stem cell (ESC) reporter line has been used to generate motor neurons for studying $\mathrm{ALS}^{[56,57]}$. The advances in genetic engineering methods such as the use of zinc finger nuclease $(\mathrm{ZFN})^{[58]}$ and transcription activator-like effector nucleases (TALEN) ${ }^{[59]}$ offer great tools for lineage-specific labeling in iPSCs.

\section{Detection of genotype-associated disease phenotypes}

Building solid links between genetic mutations and diseasespecific phenotypes in iPSCs would provide confidence for drug discovery using these models. For neurological diseases, disease-related phenotypes can be observed via deficits in cell survival, neuronal morphology, neuronal migration/neurogenesis, synaptic function, and electrophysiological function. Biochemical changes that are directly linked to gene mutations are easily detectable. For example, reduced SMN1 protein expression was found in SMA iPSCs ${ }^{[16]}$, and a-synuclein accumulation was observed in DA neurons differentiated from iPSCs carrying either the SNCA triplication or the LRRK2 mutation $^{[42,44]}$. Cellular functional changes that are linked to disease symptoms are not easy to establish, yet they are more valuable for compound screens.

$\mathrm{HD}$ is a dominantly inherited late-onset neurodegenerative disease caused by a CAG repeat expansion in the first exon of the gene huntingtin (HTT) ${ }^{[60]}$, and it is characterized by the selective loss of medium spiny projection neurons in the striatum and cortex of the HD brain. It is generally accepted that mutant HTT with greater than 36-38 CAG repeats may mediate neurodegeneration via the generation of toxic N-terminal fragments, alterations in vesicular trafficking, mitochondrial function and transcriptional dysregulation ${ }^{[61,62]}$.

The HD Consortium ${ }^{[63]}$ generated and characterized a panel of 14 iPSC lines derived from controls and HD patients with varying numbers of CAG repeats and timeframes for the ageonset of the disease. Microarray profiling revealed that these iPSC lines have clear, reproducible CAG repeat-expansionassociated phenotypes upon differentiation, and distinctly different gene expression profiles were found between patient iPSC lines and those derived from controls. Differences in 
the gene expression profiles were also found between earlyonset HD iPSCs and late-onset iPSCs. Disease-associated changes in electrophysiology, metabolism, cell adhesion, and ultimately cell death were shown in the differentiated neural cells from HD iPSCs lines harboring both medium and longer CAG repeat expansions. Cells carrying the longer repeats were more vulnerable to cellular stressors and BDNF withdrawal when assessed using a range of assays across consortium laboratories ${ }^{[63]}$, supporting the correlation of CAG repeat lengths with disease onset.

\section{Confirmation of disease phenotypes with genetic rescue experi- ments}

The most powerful proof of disease phenotypes in iPSC models comes from the genetic rescue of the phenotypes by correcting gene mutations, as illustrated in the case of SMA that was discussed in an earlier section ${ }^{[18]}$. Another example was given by An et al ${ }^{[64]}$, who reported that HD iPSCs were corrected through the replacement of the expanded CAG repeat with a normal repeat using homologous recombination and demonstrated the restoration of function in differentiated DARPP-32(+) neurons both in vitro and in vivo. Moreover, the genetic correction of HD iPSCs normalized the pathogenic HD signaling pathways and reversed the relevant disease phenotypes such as the susceptibility to cell death and the altered mitochondrial bioenergetics in neural stem cells $^{[64]}$. DA neurons differentiated from PINK1 iPSCs ${ }^{[46,47]}$ displayed impaired mitochondrial function, as shown by the disabled stress-induced mitochondrial translocation of parkin, increased mitochondrial copy number and upregulation of PGC-1a. Importantly, these phenotypes were rescued by the lentiviral expression of wild-type PINK1 in neurons derived from PINK1 iPSCs $^{[47]}$. Rescue experiments can therefore provide definitive proof that the phenotypes observed in the iPSC models are indeed due to the specific genetic defects.

\section{The iPSC technology-related challenges for disease modeling}

As many labs are generating disease-specific iPSCs, clone variations have been observed to affect the differentiation potential and phenotypes of iPSCs. For example, Boulting et $a{ }^{[65]}$ generated 16 iPSC lines from seven different individuals of varying age, sex and health status. After characterization, three of the iPSC lines were found to be resistant to neuronal differentiation. In this section, we will discuss the main factors causing phenotype variations among iPSC clones and suggest possible solutions for them.

\section{Genetic aberrations}

Currently, most iPSCs are generated using reprogramming factors transduced by integrating viral vectors such as lentivirus or retrovirus, which often cause mutations at the integration sites or other genetic aberrations such as copy number variations or abnormal karyotypes ${ }^{[66]}$. Genetic alteration by random viral integration may affect the differentiation of iPSCs as well as their phenotypes. For example, Somma et $a l^{[67]}$ found that the removal of the reprogramming transgenes improved the developmental potential of iPSCs and augmented their capacity to undergo directed differentiation in vitro.

Strategies have been developed for the generation of transgene-free iPSCs to minimize or eliminate genetic variations. Non-integrative approaches using excisable lentiviral or transposon vectors ${ }^{[68]}$, non-integrating RNA viruses or Sendai viruses $^{[69]}$, episomal vectors ${ }^{[70]}$, mRNA transfections ${ }^{[71]}$, and recombinant protein ${ }^{[72]}$ have been developed for reprogramming. In addition, a series of small molecules such as 5-aza-dc, vitamin C, valproic acid and forskolin have been reported to improve iPSC reprogramming efficiencies ${ }^{[73]}$. Successful examples of integration-free patient iPSCs include those from SCZD patients harboring a DISC1 mutation ${ }^{[7]}$ and idiopathic PD patients ${ }^{[75]}$.

\section{Epigenetic memory in iPSCs}

Several groups have shown that iPSCs retain epigenetic memory from their donor cells ${ }^{[76-79]}$. Lister et al ${ }^{[77]}$ discovered that iPSCs displayed significant reprogramming variability, including somatic memory and aberrant reprogramming of DNA methylation, which were independent of the reprogramming techniques. This type of epigenetic memory would influence the differentiation potential of iPSCs. For example, BarNur et $a l^{[76]}$ reported that $\beta$-cell-derived iPSCs displayed an increased ability to differentiate into insulin-producing cells compared with ESCs and isogenic non- $\beta$ cell-derived iPSCs. Some studies have indicated that long-term culture of iPSCs with increased passage number may decrease the differences between iPSCs and ESCs, followed by the loss of parental cell line characteristics ${ }^{[78]}$.

\section{The absence of well-defined controls}

Currently, iPSCs from age-matched, unaffected donors are usually chosen as controls in iPSC disease models. However, these controls are not ideal for iPSC disease models as they usually have different genetic backgrounds and a different history of risk factor exposure. The use of gene editing technologies such as ZFN and TALEN to correct disease genes in iPSCs might be helpful to generate lines which can serve as isogenic controls ${ }^{[80]}$. In addition, temporal changes in differentiated cells from disease or control iPSCs can reveal subtle phenotypes in a very sensitive way if compared with the baselines of each cell type. For example, selective motor neuron death occurred in 6-week differentiated SMA neurons, but not in 4 -week differentiated ones ${ }^{[16]}$. Moreover, a recent study that established iPSC lines from centenarians ${ }^{[81]}$ may provide valid controls for studying late-onset diseases using iPSC models, as the donors were presumed to have no serious disease risk factors.

\section{Lack of large numbers of iPSC lines}

As each individual patient has a distinct genetic background and many pathways contribute to the cellular phenotypes, it is often difficult to pinpoint a cellular phenotype to a specific 
gene mutation. This can be further complicated by the various co-morbidities in individuals. The key disease-relevant phenotypes should be shared by iPSCs bearing the same gene mutations even though the cells were derived from patients with different genetic backgrounds. The discovery of common cellular phenotypes from a large panel of patient iPSCs could increase the reliability of the cellular defects associated with the gene mutations carried by the iPSCs. Drug screening based on these disease phenotypes beyond clone and donor variations would be reliable and ideal for discovering new drugs. As an example, the HD consortium obtained a total of 14 iPSC lines and demonstrated consistent phenotypes, with severity correlating with the extent of the genetic mutations (ie, CAG repeat expansion) ${ }^{[63]}$.

Therefore, it is important to use more than one iPSC line from each patient and control, and select a diverse group of patients with different genetic backgrounds to ensure that disease-specific cellular phenotypes are detected beyond the normal variability of iPSC-derived cells through an appropriate number of iPSC lines.

\section{Other stem cell-based approaches for disease modeling beyond patient-specific iPSCs}

In addition to the exciting progress made in patient-specific iPSCs for disease modeling, a few other technical breakthroughs can likely offer convenience, broaden patient scope, and even tighten disease relevance. We will review some of these approaches here.

\section{Disease modeling by challenging cells derived from normal iPSCs or ESCs}

Toxin challenge and the overexpression of disease genes have been widely used in cell lines or primary rodent cells for disease modeling. True human cells can now be used for these experiments due to the availability of iPSCs and ESCs, which might represent a major improvement in such established approaches. Xu et al ${ }^{[82]}$ modeled neuronal loss in human AD by challenging forebrain neurons differentiated from human iPSCs with $A \beta_{1-42}$ aggregates. Several small molecules were identified as potent inhibitors of the cellular toxicity elicited by the $A \beta$ aggregates via the screening of a few compound sets ${ }^{[82]}$. Another approach is the generation of a panel of isogenic cell lines by expressing disease-causing transgenes in wild-type ESCs or iPSCs. For example, Soldner et a ${ }^{[83]}$ have established the A53T (G209A) a-synuclein mutation in human ESCs using ZFN technologies.

\section{Disease modeling using desired cells differentiated from patient} adult stem cells

One of the most exciting advances in disease modeling comes from isolating adult stem cells directly from the postmortem tissues of patients. Haidet-Phillips et $a l^{[84]}$ isolated adult NPCs from the lumbar spinal cord tissue of ALS patients, and the astrocytes derived from those NPCs were co-cultured with lineage-labeled motor neurons from non-ALS-affected ESCs. The astrocytes derived from the NPCs of familial ALS patients carrying the SOD1 mutation demonstrated significant toxic effects to motor neurons. Unexpectedly, astrocytes derived from the NPCs of sporadic ALS patients also demonstrated toxicity to motor neurons, which offered a novel cell system to screen compounds with a broader scope of cell defects beyond the previous known gene mutations. As the majority of diseases are not monogenic diseases or diseases with known genetic components, the approaches demonstrated here could have a great impact on disease mechanism studies as well as compound screens if widely adopted.

\section{Disease modeling using iNPCs and iNs directly generated from} patient somatic cells

Generating neurons or NPCs from ESCs and iPSCs is a complicated and time-consuming process that could introduce batch-to-batch variations and increase the risk of neoplasia or undesired cell types. This process can be circumvented by the direct conversion of somatic cells from one cell type to another via the ectopic expression of specifically defined transcription factors. Recently, cell types ranging from NPCs ${ }^{[85,86]}$ to neurons ${ }^{[87,88]}$, including motor neurons ${ }^{[89]}$ and DA neurons ${ }^{[90]}$, were able to be derived from human fibroblasts. These NPCs and neurons were named iNPCs and iNs, respectively. For example, Tian et al ${ }^{[86]}$ found that five different transcription factors could directly convert adult dermal fibroblasts into iNPCs, and the resulting cells possessed similar properties to the primary NPCs, including proliferation, self-renewal, differentiation, and chemotactic properties. However, this type of strategy is not sufficient to provide cells at a large enough scale for some applications, including drug screens. Additionally, this approach has the disadvantage of potentially skipping the neuronal developmental stages in which some disease phenotypes may become evident. Whether this type of technology could provide an alternative strategy for disease modeling and drug screening remains to be seen.

\section{Conclusions and perspectives}

With an ever-growing list of patient-specific iPSCs available, many attempts to use iPSCs for disease modeling and drug screening have been explored. Success in this area requires the development and characterization of reliable disease phenotypes from both iPSCs and their derivatives. Advances in iPSC technologies have reduced the phenotypic variations among iPSC clones, enabling the establishment of reliable disease models for drug screening. In addition, some alternative stem cell-based approaches such as deriving iNPCs/iNs directly from somatic cells or NPCs derived from postmortem tissues might help to establish novel neurological disease models for drug discovery. Using panels of iPSCs from broad patient populations, compounds could potentially be profiled in these cells, representing "clinical trials in test tubes" [91]. This could be a potential method by which iPSCs contribute to personalized medicine, drug testing, and predictive toxicology studies $^{[92]}$. Testing drug candidates in iPSCs carrying distinct genetic mutations of certain diseases might help to choose the appropriate patient populations for the lead molecules. Effec- 
tive patient stratification is expected to reduce clinical trial cost and also attrition rates ${ }^{[93]}$. Therefore, it is anticipated that disease modeling and compound screens on iPSC models will lead to important breakthroughs in drug discovery and development.

\section{Acknowledgements}

The authors would like to thank Jing ZHAO, Hai-yan FANG (both from GlaxoSmithKline R\&D, China), Dwight MORROW (GlaxoSmithKline, USA), Kevin J KIM (Harvard Stem Cell Institute, USA) and Lucas CHASE (Cellular Dynamics International Inc, USA) for their critical reading of the manuscript and valuable suggestions.

\section{References}

1 Mattis VB, Svendsen CN. Induced pluripotent stem cells: a new revolution for clinical neurology? Lancet Neurol 2011; 10: 383-94.

2 Wang $\mathrm{H}$, Doering LC. Induced pluripotent stem cells to model and treat neurogenetic disorders. Neural Plast 2012; 2012: 346053.

3 Ito $\mathrm{D}$, Okano H, Suzuki N. Accelerating progress in induced pluripotent stem cell research for neurological diseases. Ann Neurol 2012; 72: 167-74.

4 Takahashi K, Tanabe K, Ohnuki M, Narita M, Ichisaka T, Tomoda K, et al. Induction of pluripotent stem cells from adult human fibroblasts by defined factors. Cell 2007; 131: 861-72.

5 Takahashi K, Yamanaka S. Induction of pluripotent stem cells from mouse embryonic and adult fibroblast cultures by defined factors. Cell 2006; 126: 663-76.

6 Dolmetsch R, Geschwind DH. The human brain in a dish: the promise of iPSC-derived neurons. Cell 2011; 145: 831-4.

7 Juopperi TA, Song H, Ming GL. Modeling neurological diseases using patient-derived induced pluripotent stem cells. Future Neurol 2011; 6: 363-73.

8 Marchetto MC, Brennand KJ, Boyer LF, Gage FH. Induced pluripotent stem cells (iPSCs) and neurological disease modeling: progress and promises. Hum Mol Genet 2011; 20: R109-115.

9 Wu SM, Hochedlinger K. Harnessing the potential of induced pluripotent stem cells for regenerative medicine. Nat Cell Biol 2011; 13 : 497-505.

10 Grskovic M, Javaherian A, Strulovici B, Daley GQ. Induced pluripotent stem cells - opportunities for disease modelling and drug discovery. Nat Rev Drug Discov 2011; 10: 915-29.

11 Maury Y, Gauthier M, Peschanski M, Martinat C. Human pluripotent stem cells for disease modelling and drug screening. Bioessays 2011; 34: 61-71.

12 Chailangkarn T, Acab A, Muotri AR. Modeling neurodevelopmental disorders using human neurons. Curr Opin Neurobiol 2012; 22: 785-90.

13 Monani UR. Spinal muscular atrophy: a deficiency in a ubiquitous protein; a motor neuron-specific disease. Neuron 2005; 48: 88596.

14 Burghes AH, Beattie CE. Spinal muscular atrophy: why do low levels of survival motor neuron protein make motor neurons sick? Nat Rev Neurosci 2009; 10: 597-609.

15 Kerr DA, Nery JP, Traystman RJ, Chau BN, Hardwick JM. Survival motor neuron protein modulates neuron-specific apoptosis. Proc Natl Acad Sci U S A 2000; 97: 13312-7.

16 Ebert AD, Yu J, Rose FF Jr, Mattis VB, Lorson CL, Thomson JA, et al. Induced pluripotent stem cells from a spinal muscular atrophy patient. Nature 2009; 457: 277-80.
17 Sareen D, Ebert AD, Heins BM, McGivern JV, Ornelas L, Svendsen $\mathrm{CN}$. Inhibition of apoptosis blocks human motor neuron cell death in a stem cell model of spinal muscular atrophy. PLoS One 2012; 7: e39113.

18 Chang T, Zheng W, Tsark W, Bates S, Huang H, Lin RJ, et al. Brief report: phenotypic rescue of induced pluripotent stem cell-derived motoneurons of a spinal muscular atrophy patient. Stem Cells 2011; 29: 2090-3.

19 Costa Mdo C, Paulson HL. Toward understanding Machado-Joseph disease. Prog Neurobiol 2012; 97: 239-57.

20 Gatchel JR, Zoghbi HY. Diseases of unstable repeat expansion: mechanisms and common principles. Nat Rev Genet 2005; 6: 74355.

21 Koch P, Breuer P, Peitz M, Jungverdorben J, Kesavan J, Poppe D, et al. Excitation-induced ataxin-3 aggregation in neurons from patients with Machado-Joseph disease. Nature 2011; 480: 543-6.

22 Zhang N, An MC, Montoro D, Ellerby LM. Characterization of human huntington's disease cell model from induced pluripotent stem cells. PLoS Curr 2010; 2: RRN1193.

23 Urbach A, Bar-Nur O, Daley GQ, Benvenisty N. Differential modeling of fragile $X$ syndrome by human embryonic stem cells and induced pluripotent stem cells. Cell Stem Cell 2010; 6: 407-11.

24 Chamberlain SJ, Chen PF, Ng KY, Bourgois-Rocha F, Lemtiri-Chlieh $\mathrm{F}$, Levine ES, et al. Induced pluripotent stem cell models of the genomic imprinting disorders Angelman and Prader-Willi syndromes. Proc Natl Acad Sci U S A 2010; 107: 17668-73.

25 Kazuki Y, Hiratsuka M, Takiguchi M, Osaki M, Kajitani N, Hoshiya $\mathrm{H}$, et al. Complete genetic correction of ips cells from Duchenne muscular dystrophy. Mol Ther 2010; 18: 386-93.

26 Lee G, Papapetrou EP, Kim H, Chambers SM, Tomishima MJ, Fasano CA, et al. Modelling pathogenesis and treatment of familial dysautonomia using patient-specific iPSCs. Nature 2009; 461: 402-6.

27 Park IH, Arora N, Huo H, Maherali N, Ahfeldt T, Shimamura A, et al. Disease-specific induced pluripotent stem cells. Cell 2008; 134: 877-86.

28 Song B, Sun G, Herszfeld D, Sylvain A, Campanale NV, Hirst CE, et al. Neural differentiation of patient specific iPS cells as a novel approach to study the pathophysiology of multiple sclerosis. Stem Cell Res 2011; 8: 259-73.

29 Selkoe DJ. Alzheimer's disease. Cold Spring Harb Perspect Biol 2011; 3 (7).

30 Israel MA, Yuan SH, Bardy C, Reyna SM, Mu Y, Herrera C, et al. Probing sporadic and familial Alzheimer's disease using induced pluripotent stem cells. Nature 2012; 482: 216-20.

31 Shi Y, Kirwan P, Smith J, MacLean G, Orkin SH, Livesey FJ. A human stem cell model of early Alzheimer's disease pathology in down syndrome. Sci Transl Med 2012; 4: 124-9.

32 Yagi T, Ito D, Okada Y, Akamatsu W, Nihei Y, Yoshizaki T, et al. Modeling familial Alzheimer's disease with induced pluripotent stem cells. Hum Mol Genet 2011; 20: 4530-9.

33 Ilieva H, Polymenidou M, Cleveland DW. Non-cell autonomous toxicity in neurodegenerative disorders: ALS and beyond. J Cell Biol 2009; 187: 761-72.

34 Di Giorgio FP, Boulting GL, Bobrowicz S, Eggan KC. Human embryonic stem cell-derived motor neurons are sensitive to the toxic effect of glial cells carrying an ALS-causing mutation. Cell Stem Cell 2008; 3: 637-48.

35 Marchetto MC, Muotri AR, Mu Y, Smith AM, Cezar GG, Gage FH. Noncell-autonomous effect of human SOD1 G37R astrocytes on motor neurons derived from human embryonic stem cells. Cell Stem Cell 
2008; 3: 649-57.

36 Dimos JT, Rodolfa KT, Niakan KK, Weisenthal LM, Mitsumoto H, Chung $\mathrm{W}$, et al. Induced pluripotent stem cells generated from patients with ALS can be differentiated into motor neurons. Science 2008; 321: 1218-21.

37 Bilican B, Serio A, Barmada SJ, Nishimura AL, Sullivan GJ, Carrasco M, et al. Mutant induced pluripotent stem cell lines recapitulate aspects of TDP-43 proteinopathies and reveal cell-specific vulnerability. Proc Natl Acad Sci U S A 2012; 109: 5803-8.

38 Egawa N, Kitaoka S, Tsukita K, Naitoh M, Takahashi K, Yamamoto $\mathrm{T}$, et al. Drug screening for ALS using patient-specific induced pluripotent stem cells. Sci Transl Med 2012; 4: 145ra104.

39 Majumdar D, Gao Y, Li D, Webb DJ. Co-culture of neurons and glia in a novel microfluidic platform. J Neurosci Methods 2011; 196: 38-44.

40 Kunze A, Giugliano M, Valero A, Renaud P. Micropatterning neural cell cultures in 3D with a multi-layered scaffold. Biomaterials 2011; 32: $2088-98$.

41 Dawson TM, Dawson VL. Molecular pathways of neurodegeneration in Parkinson's disease. Science 2003; 302: 819-22.

42 Byers B, Cord B, Nguyen HN, Schule B, Fenno L, Lee PC, et al. SNCA triplication Parkinson's patient's iPSC-derived DA neurons accumulate alpha-synuclein and are susceptible to oxidative stress. PLoS One 2011; 6: e26159.

43 Devine MJ, Ryten M, Vodicka P, Thomson AJ, Burdon T, Houlden $\mathrm{H}$, et al. Parkinson's disease induced pluripotent stem cells with triplication of the alpha-synuclein locus. Nat Commun 2011; 2: 440.

44 Nguyen HN, Byers B, Cord B, Shcheglovitov A, Byrne J, Gujar P, et al. LRRK2 mutant iPSC-derived DA neurons demonstrate increased susceptibility to oxidative stress. Cell Stem Cell 2011; 8: 267-80.

45 Sanchez-Danes A, Richaud-Patin Y, Carballo-Carbajal I, JimenezDelgado S, Caig C, Mora S, et al. Disease-specific phenotypes in dopamine neurons from human iPS-based models of genetic and sporadic Parkinson's disease. EMBO Mol Med 2012; 4: 380-95.

46 Cooper O, Seo H, Andrabi S, Guardia-Laguarta C, Graziotto J, Sundberg $\mathrm{M}$, et al. Pharmacological rescue of mitochondrial deficits in iPSC-derived neural cells from patients with familial Parkinson's disease. Sci Transl Med 2012; 4: 141ra190.

47 Seibler P, Graziotto J, Jeong H, Simunovic F, Klein C, Krainc D. Mitochondrial Parkin recruitment is impaired in neurons derived from mutant PINK1 induced pluripotent stem cells. J Neurosci 2011; 31: 5970-6.

48 Imaizumi Y, Okada Y, Akamatsu W, Koike M, Kuzumaki N, Hayakawa H, et al. Mitochondrial dysfunction associated with increased oxidative stress and alpha-synuclein accumulation in PARK2 iPSC-derived neurons and postmortem brain tissue. Mol Brain 2012; 5: 35.

49 Schmitt A, Hasan A, Gruber O, Falkai P. Schizophrenia as a disorder of disconnectivity. Eur Arch Psychiatry Clin Neurosci 2011; 261 Suppl 2: S150-154.

50 Brennand KJ, Gage FH. Concise review: the promise of human induced pluripotent stem cell-based studies of schizophrenia. Stem Cells 2011; 29: 1915-22.

51 Brennand KJ, Simone A, Jou J, Gelboin-Burkhart C, Tran N, Sangar $\mathrm{S}$, et al. Modelling schizophrenia using human induced pluripotent stem cells. Nature 2011; 473: 221-5.

52 Bissonnette CJ, Lyass L, Bhattacharyya BJ, Belmadani A, Miller RJ, Kessler JA. The controlled generation of functional basal forebrain cholinergic neurons from human embryonic stem cells. Stem Cells 2011; 29: 802-11.

53 Chambers SM, Fasano CA, Papapetrou EP, Tomishima M, Sadelain M, Studer L. Highly efficient neural conversion of human ES and iPS cells by dual inhibition of SMAD signaling. Nat Biotechnol 2009; 27 :
275-80.

54 Hester ME, Murtha MJ, Song S, Rao M, Miranda CJ, Meyer K, et al. Rapid and efficient generation of functional motor neurons from human pluripotent stem cells using gene delivered transcription factor codes. Mol Ther 2009; 19: 1905-12.

55 Zeng H, Guo M, Martins-Taylor K, Wang X, Zhang Z, Park JW, et al. Specification of region-specific neurons including forebrain glutamatergic neurons from human induced pluripotent stem cells. PLoS One 2010; 5: e11853.

56 Wichterle H, Lieberam I, Porter JA, Jessell TM. Directed differentiation of embryonic stem cells into motor neurons. Cell 2002; 110: 385-97.

57 Karumbayaram S, Kelly TK, Paucar AA, Roe AJ, Umbach JA, Charles A, et al. Human embryonic stem cell-derived motor neurons expressing SOD1 mutants exhibit typical signs of motor neuron degeneration linked to ALS. Dis Model Mech 2009; 2: 189-95.

58 Hockemeyer D, Soldner F, Beard C, Gao Q, Mitalipova M, DeKelver $\mathrm{RC}$, et al. Efficient targeting of expressed and silent genes in human ESCs and iPSCs using zinc-finger nucleases. Nat Biotechnol 2009; 27: 851-7.

59 Hockemeyer D, Wang H, Kiani S, Lai CS, Gao Q, Cassady JP, et al. Genetic engineering of human pluripotent cells using TALE nucleases. Nat Biotechnol 2011; 29: 731-4.

60 The Huntington's Disease Collaborative Research Group. A novel gene containing a trinucleotide repeat that is expanded and unstable on Huntington's disease chromosomes. Cell 1993; 72: 971-83.

61 Hackam AS, Singaraja R, Wellington CL, Metzler M, McCutcheon K, Zhang $\mathrm{T}$, et al. The influence of huntingtin protein size on nuclear localization and cellular toxicity. J Cell Biol 1998; 141: 1097-105.

62 Wellington CL, Ellerby LM, Hackam AS, Margolis RL, Trifiro MA, Singaraja $\mathrm{R}$, et al. Caspase cleavage of gene products associated with triplet expansion disorders generates truncated fragments containing the polyglutamine tract. J Biol Chem 1998; 273: 915867.

63 The HD iPSC Consortium. Induced pluripotent stem cells from patients with Huntington's disease show CAG-repeat-expansionassociated phenotypes. Cell Stem Cell 2012; 11: 264-78.

64 An MC, Zhang N, Scott G, Montoro D, Wittkop T, Mooney S, et al. Genetic correction of Huntington's disease phenotypes in induced pluripotent stem cells. Cell Stem Cell 2012; 11: 253-63.

65 Boulting GL, Kiskinis E, Croft GF, Amoroso MW, Oakley DH, Wainger $\mathrm{BJ}$, et al. A functionally characterized test set of human induced pluripotent stem cells. Nat Biotechnol 2011; 29: 279-86.

66 Laurent LC, Ulitsky I, Slavin I, Tran H, Schork A, Morey R, et al. Dynamic changes in the copy number of pluripotency and cell proliferation genes in human ESCs and iPSCs during reprogramming and time in culture. Cell Stem Cell 2010; 8: 106-18.

67 Sommer CA, Sommer AG, Longmire TA, Christodoulou C, Thomas DD, Gostissa $\mathrm{M}$, et al. Excision of reprogramming transgenes improves the differentiation potential of iPS cells generated with a single excisable vector. Stem Cells 2010; 28: 64-74.

68 Kaji K, Norrby K, Paca A, Mileikovsky M, Mohseni P, Woltjen K. Virusfree induction of pluripotency and subsequent excision of reprogramming factors. Nature 2009; 458: 771-5.

69 Fusaki N, Ban H, Nishiyama A, Saeki K, Hasegawa M. Efficient induction of transgene-free human pluripotent stem cells using a vector based on Sendai virus, an RNA virus that does not integrate into the host genome. Proc Jpn Acad Ser B Phys Biol Sci 2009; 85: 348-62.

$70 \mathrm{Yu} \mathrm{J,} \mathrm{Hu} \mathrm{K,} \mathrm{Smuga-Otto} \mathrm{K,} \mathrm{Tian} \mathrm{S,} \mathrm{Stewart} \mathrm{R,} \mathrm{Slukvin,} \mathrm{II,} \mathrm{et} \mathrm{al.}$ Human induced pluripotent stem cells free of vector and transgene sequences. Science 2009; 324: 797-801. 
71 Warren L, Manos PD, Ahfeldt T, Loh YH, Li H, Lau F, et al. Highly efficient reprogramming to pluripotency and directed differentiation of human cells with synthetic modified mRNA. Cell Stem Cell 2010; 7: 618-30.

72 Zhou H, Wu S, Joo JY, Zhu S, Han DW, Lin T, et al. Generation of induced pluripotent stem cells using recombinant proteins. Cell Stem Cell 2009; 4: 381-4.

73 Huangfu D, Maehr R, Guo W, Eijkelenboom A, Snitow M, Chen AE, et al. Induction of pluripotent stem cells by defined factors is greatly improved by small-molecule compounds. Nat Biotechnol 2008; 26 : 795-7.

74 Chiang CH, Su Y, Wen Z, Yoritomo N, Ross CA, Margolis RL, et al. Integration-free induced pluripotent stem cells derived from schizophrenia patients with a DISC1 mutation. Mol Psychiatry 2011; 16: 358-60.

75 Soldner F, Hockemeyer D, Beard C, Gao Q, Bell GW, Cook EG, et al. Parkinson's disease patient-derived induced pluripotent stem cells free of viral reprogramming factors. Cell 2009; 136: 964-77.

76 Bar-Nur O, Russ HA, Efrat S, Benvenisty N. Epigenetic memory and preferential lineage-specific differentiation in induced pluripotent stem cells derived from human pancreatic islet beta cells. Cell Stem Cell 2011; 9: 17-23.

77 Lister R, Pelizzola M, Kida YS, Hawkins RD, Nery JR, Hon G, et al. Hotspots of aberrant epigenomic reprogramming in human induced pluripotent stem cells. Nature 2011; 471: 68-73.

78 Nishino K, Toyoda M, Yamazaki-Inoue M, Fukawatase Y, Chikazawa $\mathrm{E}$, Sakaguchi $\mathrm{H}$, et al. DNA methylation dynamics in human induced pluripotent stem cells over time. PLoS Genet 2011; 7: e1002085.

79 Ohi Y, Qin H, Hong C, Blouin L, Polo JM, Guo T, et al. Incomplete DNA methylation underlies a transcriptional memory of somatic cells in human iPS cells. Nat Cell Biol 2011; 13: 541-9.

80 Zou J, Maeder ML, Mali P, Pruett-Miller SM, Thibodeau-Beganny S, Chou BK, et al. Gene targeting of a disease-related gene in human induced pluripotent stem and embryonic stem cells. Cell Stem Cell 2009; 5: 97-110.

81 Yagi T, Kosakai A, Ito D, Okada Y, Akamatsu W, Nihei Y, et al. Establishment of induced pluripotent stem cells from centenarians for neurodegenerative disease research. PLoS One 2012; 7: e41572.

82 Xu X, Lei Y, Luo J, Wang J, Zhang S, Yang X, et al. Prevention of $\beta$-amyloid induced toxicity in human iPS cell-derived neurons by inhibition of cyclin-dependent kinases and associated cell cyle events. Stem Cell Res 2013; 10: 213-27.

83 Soldner F, Laganiere J, Cheng AW, Hockemeyer D, Gao Q, Alagappan $\mathrm{R}$, et al. Generation of isogenic pluripotent stem cells differing exclusively at two early onset Parkinson point mutations. Cell 2011; 146: 318-31.

84 Haidet-Phillips AM, Hester ME, Miranda CJ, Meyer K, Braun L, Frakes A, et al. Astrocytes from familial and sporadic ALS patients are toxic to motor neurons. Nat Biotechnol 2011; 29: 824-8.

85 Lee ST, Chu K, Jung KH, Song YM, Jeon D, Kim SU, et al. Direct generation of neurosphere-like cells from human dermal fibroblasts. PLoS One 2011; 6: e21801.

86 Tian C, Ambroz RJ, Sun L, Wang Y, Ma K, Chen Q, et al. Direct conversion of dermal fibroblasts into neural progenitor cells by a novel cocktail of defined factors. Curr Mol Med 2012; 12: 126-37.

87 Abdullah Al, Pollock A, Sun T. The path from skin to brain: generation of functional neurons from fibroblasts. Mol Neurobiol 2012; 45: 586-95.

88 Vierbuchen T, Ostermeier A, Pang ZP, Kokubu Y, Sudhof TC, Wernig M. Direct conversion of fibroblasts to functional neurons by defined factors. Nature 2010; 463: 1035-41.

89 Son EY, Ichida JK, Wainger BJ, Toma JS, Rafuse VF, Woolf CJ, et al.
Conversion of mouse and human fibroblasts into functional spinal motor neurons. Cell Stem Cell 2011; 9: 205-18.

90 Pfisterer U, Kirkeby A, Torper O, Wood J, Nelander J, Dufour A, et al. Direct conversion of human fibroblasts to dopaminergic neurons. Proc Natl Acad Sci U S A 2011; 108: 10343-8.

91 Han SS, Williams LA, Eggan KC. Constructing and deconstructing stem cell models of neurological disease. Neuron 2011; 70: 62644.

92 Rubin LL, Haston KM. Stem cell biology and drug discovery. BMC Biol 2011; 9: 42.

93 Kola I, Landis J. Can the pharmaceutical industry reduce attrition rates? Nat Rev Drug Discov 2004; 3: 711-5.

94 Koch P, Breuer P, Peitz M, Jungverdorben J, Kesavan J, Poppe D, et al. Excitation-induced ataxin-3 aggregation in neurons from patients with Machado-Joseph disease. Nature 2011; 480: 543-6.

95 Camnasio S, Carri AD, Lombardo A, Grad I, Mariotti C, Castucci A, et al. The first reported generation of several induced pluripotent stem cell lines from homozygous and heterozygous Huntington's disease patients demonstrates mutation related enhanced lysosomal activity. Neurobiol Dis 2012; 46: 41-51.

96 Juopperi TA, Kim WR, Chiang $\mathrm{CH}$, Yu H, Margolis RL, Ross CA, et al. Astrocytes generated from patient induced pluripotent stem cells recapitulate features of Huntington's disease patient cells. Mol Brain 2012; 5: 17.

97 Mitne-Neto M, Machado-Costa M, Marchetto MC, Bengtson $\mathrm{MH}$, Joazeiro CA, Tsuda $\mathrm{H}$, et al. Downregulation of VAPB expression in motor neurons derived from induced pluripotent stem cells of ALS8 patients. Hum Mol Genet 2011; 20: 3642-52.

98 Ananiev G, Williams EC, Li H, Chang Q. Isogenic pairs of wild type and mutant induced pluripotent stem cell (iPSC) lines from Rett syndrome patients as in vitro disease model. PLoS One 2011; 6: e25255.

99 Cheung AY, Horvath LM, Grafodatskaya D, Pasceri P, Weksberg R, Hotta A, et al. Isolation of MECP2-null rett syndrome patient hiPS cells and isogenic controls through X-chromosome inactivation. Hum Mol Genet 2011; 20: 2103-15.

100 Marchetto MC, Carromeu C, Acab A, Yu D, Yeo GW, Mu Y, et al. A model for neural development and treatment of Rett syndrome using human induced pluripotent stem cells. Cell 2010; 143: 527-39.

101 Muotri AR, Marchetto MC, Coufal NG, Oefner R, Yeo G, Nakashima $\mathrm{K}$, et al. L1 retrotransposition in neurons is modulated by MeCP2. Nature 2010; 468: 443-6.

102 Ricciardi S, Ungaro F, Hambrock M, Rademacher N, Stefanelli G, Brambilla D, et al. CDKL5 ensures excitatory synapse stability by reinforcing NGL-1-PSD95 interaction in the postsynaptic compartment and is impaired in patient iPSC-derived neurons. Nat Cell Biol 2012; 14: 911-23.

103 Liu GH, Qu J, Suzuki K, Nivet E, Li M, Montserrat N, et al. Progressive degeneration of human neural stem cells caused by pathogenic LRRK2. Nature 2012; 491: 603-7.

104 Koch P, Tamboli IY, Mertens J, Wunderlich P, Ladewig J, Stuber K, et al. Presenilin-1 L166P mutant human pluripotent stem cellderived neurons exhibit partial loss of gamma-secretase activity in endogenous amyloid-beta generation. Am J Pathol 2012; 180 : 2404-16.

This work is licensed under the Creative Commons Attribution-NonCommercial-No Derivative Works 3.0 Unported License. To view a copy of this license, visit http://creativecommons.org/licenses/by-ncnd/3.0/ 